\title{
Chemoradiotherapy or chemotherapy as adjuvant treatment for resected gastric cancer: should we use selection criteria?
}

\author{
Houyem Mansouri ${ }^{1}$, Ines Zemni ${ }^{1,2}$, Leila Achouri ${ }^{3}$, Najet Mahjoub ${ }^{4}$, Mohamed Ali Ayedi ${ }^{1,2}$, \\ Ines Ben Safta ${ }^{1,2}$, Tarek Ben Dhiab ${ }^{1}$, Riadh Chargui ${ }^{1}$, Khaled Rahal ${ }^{1}$ \\ ${ }^{1}$ Department of Surgical Oncology, Salah Azaiez institute of oncology, Faculty of Medicine of Tunis, University of Tunis El Manar, Tunisia \\ ${ }^{2}$ Laboratory of Microorganisms and Active Biomolecules, Faculty of sciences, University of Tunis El Manar, Tunisia \\ ${ }^{3}$ Department of surgical oncology, Regional Hospital of Jendouba, Tunisia \\ ${ }^{4}$ Department of medical oncology, Regional Hospital of Jendouba, Tunisia
}

\begin{abstract}
Background: The management of gastric adenocarcinoma is essentially based on surgery followed by adjuvant treatment. Adjuvant chemotherapy (CT) as well as chemoradiotherapy (CTRT) have proven their effectiveness in survival outcomes compared to surgery alone. However, there is little data comparing the two adjuvant approaches. This study aimed to compare the prognosis and survival outcomes of patients with gastric adenocarcinoma operated and treated by adjuvant radiochemotherapy or chemotherapy

Materials and methods: We retrospectively evaluated 80 patients with locally advanced gastric cancer (LGC) who received adjuvant treatment. We compared survival outcomes and patterns of recurrence of 53 patients treated by CTRT and those of 27 patients treated by $\mathrm{CT}$.

Results: After a median follow-up of 38.48 months, CTRT resulted in a significant improvement of the 5-year PFS $(60.9 \%$ vs. $36 \%, p=0.03)$ and the 5 -year OS $(55.9 \%$ vs. $33 \%, p=0.015)$ compared to adjuvant CT. The 5-year OS was significantly increased by adjuvant CTRT $(p=0.046)$ in patients with lymph node metastasis, and particularly those with advanced $p N$ stage $(p=0.0078)$ and high lymph node ratio (LNR) exceeding $25 \%(p=0.012)$. Also, there was a significant improvement of the PFS of patients classified pN2-N3 ( $p=0.022)$ with a high LNR ( $p=0.018)$. CTRT was also associated with improved OS and PFS in patients with lymphovascular and perineural invasion (LVI and PNI) compared to chemotherapy.

Conclusion: There is a particular survival benefit of adding radiotherapy to chemotherapy in patients with selected criteria such as lymph node involvement, high LNR LVI, and PNI.
\end{abstract}

Key words: gastric cancer; chemoradiotherapy; chemotherapy; survival

Rep Pract Oncol Radiother 2021;26(2):266-280

\section{Introduction}

Gastric cancer is the fifth most commonly diagnosed cancer in the world and the third leading cause of death related to cancer, representing a real health problem worldwide [1]. The overall survival rate of patients who have undergone only surgery is around $45 \%$ at 5 years and has undergone little change over the past decade. Local recurrences on the tumor bed, on the anastomosis, and in the locoregional lymph nodes occur in 40 to $65 \%$ of patients after resection for curative purposes. To compensate for this, an extension of the surgical procedure was recommended without reaching the

Address for correspondence: Ines Zemni, MD, Department of surgical oncology, Salah Azaiez Institute, Bab Saadoun, Boulevard 9 Avril 1938 Tunis 1006, Tunisia, 0021625 560736, e-mail: ines.zemni@yahoo.fr, ines.zemni81@gmail.com 
goal of improving survival or reducing the rate of locoregional recurrence $[2,3]$. Thus, for patients with stage $>I B$, who are at high risk of recurrence, it is undoubtedly necessary that an adjuvant treatment is offered after surgery $[2,4]$. The gastrointestinal cancer intergroup (INT-0116) was the first phase III trial to demonstrate that adjuvant concomitant radio-chemotherapy improves recurrence-free survival and overall survival [5]. On the other hand, several meta-analyses have demonstrated the survival benefit of adjuvant chemotherapy in gastric cancer [6-8]. Furthermore, two randomized controlled phase III clinical trials showed that adjuvant therapy prolonged survival and decreased recurrence $[5,9]$. Clinical trials have also directly compared postoperative CT alone with CRT for patients with locally advanced gastric cancer and the meta-analysis of three randomized clinical trials showed that CRT reduced the risk of locoregional relapses, but without significant improvement in distant relapse and overall survival [10]. Results of the ARTIST phase III randomized controlled trial showed that both adjuvant CT and CTRT are tolerated and equally beneficial in preventing relapse and suggested that CTRT had significantly improved the DFS in patients with node-positive disease and with intestinal-type [11]. Given these results, the choice of the optimal adjuvant therapeutic attitude remains a subject of controversy.

This study aimed to compare retrospectively the prognosis and survival outcomes of patients with gastric adenocarcinoma operated and treated by adjuvant radio-chemotherapy or chemotherapy alone and to assess the toxicity and safety of the tow treatment modalities to identify suitable patients for an intensified adjuvant treatment.

\section{Materials and methods}

\section{Patients}

We retrospectively evaluated 80 patients with LGC who received adjuvant treatment from January 2005 to December 2015. Patients were eligible for analysis if they had histological confirmation of gastric cancer, had curative gastrectomy with nodal dissection. Exclusion criteria included the use of neoadjuvant treatment, metastatic disease at diagnosis, and patients with coexisting malignancies or those who could not tolerate the adjuvant treatment because of other systemic diseases.
We started identifying medical files, clinic (age, gender, reason of counseling, WHO status), endoscopic data (tumors site, size, aspect), tumor markers (CA 19-9 and CEA level), histological data (histological type, tumors size, differentiation grade, number of removed nodes, parietal infiltration depth, lymphovascular invasion (LVI), perineural tumor invasion (PNI), lymph node status and the lymph node ratio (LNR) that corresponded to the ratio between metastatic and dissected lymph nodes. The lymph nodes metastasis ( $\mathrm{N}$ stage) and the depth of invasion ( $\mathrm{T}$ stage) were classified according to the TNM staging system 8th edition elaborated by the American Joint Committee on Cancer/International Union Against Cancer (AJCC/UICC) TNM staging system (AJCC/UICC). In this study, Histological classification was based on the WHO classification and Lauren classification with 3 subgroups: intestinal type, diffuse type, and mixed type [12]. Poorly differentiated tumors included moderately differentiated tubular adenocarcinoma, independent signet ring cells adenocarcinoma, and mucinous adenocarcinoma.

\section{Surgical procedure}

The surgical variables included the type of procedure (total versus partial gastrectomy), the extent of lymph node dissection (D0, D1.5, and D2) based on the different updated versions of the Japanese Gastric Cancer Treatment Guidelines [13-15]. Lymphadenectomy was classified into three types according to the site of the tumor and the type of gastrectomy: D1 dissection, D1.5 dissection, and D2 dissection. A D1.5 lymphadenectomy corresponds to a D2 lymphadenectomy with no dissection of the hilar and the splenic artery (relay 10 and 11). Splenectomy was performed in cases of metastatic lymph nodes at the hilum of the spleen or because of iatrogenic injury. The extent of stomach resection was related to the primary tumor site: total gastrectomy was performed in all proximal tumor locations and total gastric tumors, and subtotal gastrectomy was performed for distal tumor locations, provided that a 5- to $6-\mathrm{cm}$ safety margin was present. After undergoing gastrectomy, patients were assigned to either adjuvant chemo radiotherapy or adjuvant chemotherapy.

\section{Adjuvant chemotherapy}

We used 4 regimens of adjuvant chemotherapy: The LV5FU2 regimen consisted of Leucovo- 
rin $100 \mathrm{mg} / \mathrm{m}^{2}$ in 2 hours infusion days $1-2$ and 5 -FU $400 \mathrm{mg} / \mathrm{m}^{2}$ as a bolus followed by daily 22 $\mathrm{h}$ infusion of $600 \mathrm{mg} / \mathrm{m}^{2}$ every 14 days for nine cycles. The ELF regimen consisted of Folinic acid at a dose of $300 \mathrm{mg} / \mathrm{m}^{2}$ given as a 10 -minute IV infusion, followed immediately by Etoposide 120 $\mathrm{mg} / \mathrm{m}^{2}$ given as a 50 -minute IV infusion, followed by bolus 5 -FU $500 \mathrm{mg} / \mathrm{m}^{2}$ for 3 consecutive days. The cycles were repeated every 22 days. Patient treated with the FOLFOX4 regimen received an intravenous infusion of oxaliplatin $\left(85 \mathrm{mg} / \mathrm{m}^{2}\right.$ 2 hours) at day 1 , a bolus injection of Leucovorin $\left(200 \mathrm{mg} / \mathrm{m}^{2}\right)$ at days $1-2$, bolus injection of 5 -FU $\left(400 \mathrm{mg} / \mathrm{m}^{2}\right)$ at days $1-2$, and continuous intravenous infusion of 5 -FU $\left(600 \mathrm{mg} / \mathrm{m}^{2}\right)$ for 22 hours at days $1-2$.

\section{Adjuvant chemo radiotherapy}

In the CRT group, a contrast-enhanced computed tomography scan with $3 \mathrm{~mm}$-thick slices was conducted from the top of the diaphragm to the bottom of L4. The target volumes were defined as per INT 0116 protocol [16] and included the residual stomach, tumor bed, anastomosis, and the regional lymph nodes. Most radiotherapy plans were 3-dimensional conformal radiotherapy (3DCRT). Photon beams from linear accelerators with the energy of $6 / 10$ or $6 / 23 \mathrm{MV}$ were used for radiotherapy planning. The planning target (PTV) volume for each patient was generated from the clinical target volume (CTV) plus $1 \mathrm{~cm}$ margins. The prescription dose was 45-50.4 Gy, with $1.8 \mathrm{~Gy}$ daily fractions administered over 5-5.6 weeks. Associated chemotherapy regimen was based either on the INT 0116 trial using 5 cycles of intravenous bolus 5-fluorouracil and leucovorin (FUFOL regimen) before, during, and after radiotherapy, or 9 cycles of simplified LV5FU2 regimen (two to four cycles before radiotherapy, then three cycles during radiotherapy and, finally, four cycles after radiotherapy) delivered as follows: 2-hour infusion of leucovorin $200 \mathrm{mg} / \mathrm{m}^{2}$ on day 1 followed by a 400 $\mathrm{mg} / \mathrm{m}^{2}$ bolus of $5 \mathrm{FU}$ on day 1 , then a continuous infusion of $5 \mathrm{FU} 2400 \mathrm{mg} / \mathrm{m}^{2}$ over 46 hours. Some patients received 6 cycles of modified FOLFOX (three cycles during radiotherapy and three cycles after radiotherapy) administrated as follows: oxaliplatin $85 \mathrm{mg} / \mathrm{m}^{2}$, leucovorin $200 \mathrm{mg} / \mathrm{m}^{2}$, bolus fluorouracil $400 \mathrm{mg} / \mathrm{m}^{2}$, and infusional fluorouracil $1600 \mathrm{mg} / \mathrm{m}^{2}$ ).
Data regarding treatment toxicity were recorded according to the National Cancer Institute - Common Toxicity Criteria (NCI-CTC, version 4.0) (17).

\section{Statistical methods}

The categorical variables were presented as numbers and percentages. Continuous variables were expressed as the mean \pm standard deviation (SD) with ranges. Moreover, some continuous variables were converted to dichotomous variables for convenience, including the age ( $<70$ years $v s . \geq 70$ years), the weight loss $(<10 \% v s . \geq 10 \%)$, the tumor size $(<50 \mathrm{~mm} v s . \geq 50 \mathrm{~mm})$ and the NRLN $(\leq 15 \mathrm{LN}$ $v s .>15 \mathrm{LN})$. To compare the continuous variables with normal distribution we used the T-test. To compare the categorical variables we used the $\chi^{2}$ or Fisher test if the assumption for the first has not complied.

OS was defined as the time from surgery to death, or the end of follow-up and PFS was defined as the time from surgery to disease recurrence, as confirmed by using imaging. The rate and types of recurrence were compared between the two groups. Loco-regional recurrences correspond to recurrences occurring in the tumor bed, to anastomotic and lymph node recurrences. Metastatic relapses corresponded to hepatic, peritoneal, bone, pulmonary, and ovarian sites. The Progression-free survival (DFS) and overall survival (OS) rates were obtained using the Kaplan Meier methods. In the case of comparing subgroups, the log-rank test was used. We used the Statistical Package for Social Science (SPSS), version 20.0 for Windows, and a pvalue less than 0.05 was considered significant.

\section{Results}

\section{Patients' characteristics}

From January 2005 to December 2015, a total of 80 patients were eligible for the study, 53 in the CTRT group and 27 in the CT group. Baseline characteristics are summarized in Table 1. Age, gender, performance status, and tumor location as well as surgical procedures were similar between groups. However, the proportion of patients with stage III/IV disease was significantly higher in the CT cohort than in the CTRT group (85.2\% vs. 54.7\%, $\mathrm{p}=0.007$ ). Groups were not balanced regarding the lymph node status: lymph node metastasis was more frequent in the CT group than in the CTRT 
Table 1. Patient characteristics

\begin{tabular}{|c|c|c|c|c|c|}
\hline \multicolumn{2}{|l|}{ Variables } & $\begin{array}{l}\text { All patients } \\
\text { n (\%) }\end{array}$ & $\begin{array}{l}\text { CT ADJ } \\
\text { n (\%) }\end{array}$ & $\begin{array}{l}\text { CTRT } \\
\text { n (\%) }\end{array}$ & p \\
\hline \multirow{2}{*}{ Gender } & Men & $48(60 \%)$ & $13(48.1 \%)$ & $35(66 \%)$ & \multirow{2}{*}{0.122} \\
\hline & Women & $32(40 \%)$ & $14(51.9 \%)$ & 18 (34\%) & \\
\hline \multirow{3}{*}{ Age (years) } & Mean \pm SD [mm] & $59.21 \pm 12.89$ & $62.66 \pm 11.43$ & $57.45 \pm 13.33$ & 0.087 \\
\hline & $\leq 65$ & $55(68.8 \%)$ & 17 (63\%) & 38 (71.7\%) & \multirow{2}{*}{0.425} \\
\hline & $>65$ & $25(31.2 \%)$ & $10(37 \%)$ & 15 (28.3\%) & \\
\hline \multirow{2}{*}{ ASA score } & ASA1-2 & 69 (86.2\%) & 24 (88.9\%) & 45 (84.9\%) & \multirow{2}{*}{0.625} \\
\hline & ASA3 & $11(13.8 \%)$ & $3(11.1 \%)$ & $8(15.1 \%)$ & \\
\hline \multirow{2}{*}{ Weight loss } & $<10 \%$ & 31 (43.1\%) & $11(42.3 \%)$ & 20 (45.5\%) & \multirow{2}{*}{0.923} \\
\hline & $\geq 10 \%$ & 41 (56.9\%) & $15(57.7 \%)$ & 26 (56.5\%) & \\
\hline \multirow{3}{*}{ Tumor location } & Proximal & 10 (12.5\%) & $3(11.1 \%)$ & $7(13.2 \%)$ & \multirow{3}{*}{0.833} \\
\hline & Middle 1/3 & 29 (36.2\%) & $11(40.7 \%)$ & $18(34 \%)$ & \\
\hline & Distal & 41 (51.2\%) & $13(48.1 \%)$ & $28(52.8 \%)$ & \\
\hline \multirow{2}{*}{ UICC stage } & I-II & $28(35 \%)$ & $4(14.8 \%)$ & $24(45.3 \%)$ & \multirow{2}{*}{0.007} \\
\hline & III-IV & $52(65 \%)$ & 23 (85.2\%) & 29 (54.7\%) & \\
\hline \multirow{4}{*}{ UICC stage } & 1 & $2(2.5 \%)$ & $0(0 \%)$ & $2(3.8 \%)$ & \multirow{4}{*}{0.014} \\
\hline & II & 26 (32.5\%) & $4(14.8 \%)$ & 22 (41.5\%) & \\
\hline & III & 47 (58.8\%) & 19(70.4\%) & $28(52.8 \%)$ & \\
\hline & IV & $5(6.2 \%)$ & $4(14.8 \%)$ & 1 (1.9\%) & \\
\hline \multirow{4}{*}{ pT stage } & pT1 & $2(2.5 \%)$ & 0 & $2(3,8 \%)$ & \multirow{4}{*}{0.162} \\
\hline & pT2 & $18(22.5 \%)$ & $4(14,8 \%)$ & $14(26,4 \%)$ & \\
\hline & pT3 & $31(38.8 \%)$ & $9(33,3 \%)$ & $22(41,5 \%)$ & \\
\hline & pT4 & $29(36.2 \%)$ & $14(51,9 \%)$ & $15(28,3 \%)$ & \\
\hline \multirow{4}{*}{ pN stage } & No & 7 (8.8\%) & 0 & $7(13.2 \%)$ & \multirow{4}{*}{0.120} \\
\hline & N1 & $20(25 \%)$ & $8(29.6 \%)$ & $12(22.6 \%)$ & \\
\hline & N2 & $26(32.5 \%)$ & 7 (25.9\%) & $19(35.8 \%)$ & \\
\hline & N3 & 27 (33.8\%) & $12(44.4 \%)$ & $15(28.3 \%)$ & \\
\hline \multirow{2}{*}{ LN status } & $\mathrm{N}-$ & 7 (8.8\%) & 0 & $7(13.2 \%)$ & \multirow{2}{*}{0.048} \\
\hline & $\mathrm{N}+$ & 73 (91.2\%) & $27(100 \%)$ & 46 (86.8\%) & \\
\hline \multirow{2}{*}{ LNR } & $\leq 25 \%$ & $39(48.8 \%)$ & $12(44.4 \%)$ & 27 (50.9\%) & \multirow{2}{*}{0.582} \\
\hline & $>25 \%$ & 41 (51.2\%) & 15 (55.6\%) & $26(49.1 \%)$ & \\
\hline \multirow{2}{*}{ NRLN } & $<15 \mathrm{LN}$ & $16(20 \%)$ & 7 (25.9\%) & $9(17 \%)$ & \multirow{2}{*}{0.344} \\
\hline & $\geq 15 \mathrm{LN}$ & $64(80 \%)$ & $20(74.1 \%)$ & 44 (83\%) & \\
\hline Pocostion & TG & 41 (51.2\%) & $13(48.1 \%)$ & $28(52.8 \%)$ & 0607 \\
\hline 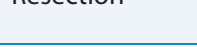 & PG & 39 (48.8\%) & $14(51.9 \%)$ & 25 (47.2\%) & 0.072 \\
\hline & D1 & $7(8.8 \%)$ & $4(14.8 \%)$ & $3(5.7 \%)$ & \\
\hline LND & D1.5 & $20(25 \%)$ & $6(22.2 \%)$ & $14(26.4 \%)$ & 0.423 \\
\hline & D2 & $53(66.2 \%)$ & $17(63 \%)$ & $36(67.9 \%)$ & \\
\hline Tumor size & $<50 \mathrm{~mm}$ & $32(40 \%)$ & $12(44.4 \%)$ & $20(37.7 \%)$ & 0592 \\
\hline [mm] & $\geq 50 \mathrm{~mm}$ & $48(60 \%)$ & $15(55.6 \%)$ & $33(62.3 \%)$ & 0.392 \\
\hline & Well & $40(50 \%)$ & $11(40.7 \%)$ & $29(54.7 \%)$ & \\
\hline Differentiation & Moderly & $23(28.8 \%)$ & $8(29.6 \%)$ & $15(28.3 \%)$ & 0.358 \\
\hline & Poorly & 17 (21.2\%) & 8 (29.6\%) & $9(17 \%)$ & \\
\hline
\end{tabular}


Table 1. Patient characteristics

\begin{tabular}{|c|c|c|c|c|c|}
\hline \multicolumn{2}{|l|}{ Variables } & $\begin{array}{c}\text { All patients } \\
\text { n (\%) }\end{array}$ & $\begin{array}{c}\text { CT ADJ } \\
\text { n (\%) }\end{array}$ & $\begin{array}{l}\text { CTRT } \\
\text { n (\%) }\end{array}$ & $\mathbf{p}$ \\
\hline \multirow{2}{*}{ Lauren type } & Intestinal & $59(73.8 \%)$ & 19 (70.4\%) & 40 (75.5\%) & \multirow{2}{*}{0.624} \\
\hline & Mixed/diffuse & $21(26.2 \%)$ & $8(29.6 \%)$ & $13(24.5 \%)$ & \\
\hline \multirow{2}{*}{ LVI } & No & $43(53.8 \%)$ & $11(40.7 \%)$ & 32 (60.4\%) & \multirow{2}{*}{0.096} \\
\hline & Yes & 37 (46.2\%) & $16(59.3 \%)$ & 31 (39.6\%) & \\
\hline \multirow{2}{*}{ PNI } & No & 44 (55\%) & $11(40.7 \%)$ & 33 (62.3\%) & \multirow{2}{*}{0.067} \\
\hline & Yes & $36(45 \%)$ & 16 (59.3\%) & 20 (37.7\%) & \\
\hline
\end{tabular}

CT ADJ - adjuvant chemotherapy; CTRT — adjuvant radiochemotherapy; NRLN — number of retrieved lymph nodes; $\mathrm{N}-$ - no lymph node metastasis , $\mathrm{N}+$ - lymph node metastasis; LVI - lymphovascular invasion; $\mathrm{PNI}$ - perineural invasion

group ( $100 \%$ vs. $86.8 \%, \mathrm{p}=0.048)$ with more advanced $\mathrm{N}$ stage, (stage $\mathrm{N} 3$ accounted for $44.4 \%$ in the CT group vs. $28.3 \%$ in the CTRT group) and more patients with a LNR exceeding $25 \%(55.6 \%$ vs. 49.1\%). The two groups were comparable regarding the histological subtype, the grade of differentiation, and tumor size. However, lymphovascular space invasion lymphovascular (LVI) were more frequent in the CT group than in the CRT group (59.3\% vs. $39.6 \%$ ) and more perineural invasion (PNI) was observed in the CT group (59.3 vs. 37.7\%). However, these differences were not statistically significant ( $\mathrm{p}=0.096$ and $\mathrm{p}=0.067$, respectively).

\section{Adjuvant treatment}

Patients assigned to adjuvant chemotherapy received variable regimens. From all, twelve patients received the LV5FU2 regimen (44.4\%), 7 patients received the FOLFOX regimen (25.9\%), 8 patients received the ELF regimen (29.6\%), and two patients received ELF regimen (7.4\%).

In the CTRT group, the most frequent associated chemotherapy was the LV5FU2 regimen in 41 patients (77.4\%), followed by the FUFOL regimen in 8 patients $(15.1 \%)$ and the FOLFOX regimen in 4 patients $(7.5 \%)$.

\section{Toxicity}

The toxicity of each treatment is summarized in Table 2. The most frequent toxicity in the CTRT group were gastrointestinal in $37.7 \%$ of cases and hematologic toxicity in the CT group $66.66 \%$ of cases. The most common grade 3 and 4 adverse events in the CT group were asthenia/anorexia (33.3\%), hematologic (29.6\%), and infectious (14.8\%); while, the most common grade 3-4 adverse event in the CTRT was gastrointestinal toxicity (13.2\%). No death during treatment was recorded in the two groups. Treatment discontinuity was recorded in $26.4 \%$ of patients in the CTRT group (14 patients) and $29.6 \%$ in the CT group (8 patients). The most common cause of treatment discontinuity in the CTRT group was toxicity in 50\% of cases followed by disease progression in $28.57 \%$ and loss of follow up in $21.42 \%$ of cases. For the CT group, treatment discontinuity was secondary to toxicity in $50 \%$ of

Table 2. Adverse events

\begin{tabular}{|l|c|c|c|c|c|c|c|c|c|c|c|c|}
\hline & \multicolumn{9}{c}{ Chemoradiation group (n= 53) } \\
Toxicity & $\begin{array}{c}\text { Grade 1 } \\
\mathrm{n}(\%)\end{array}$ & $\begin{array}{c}\text { Grade2 } \\
\mathrm{n}(\%)\end{array}$ & $\begin{array}{c}\text { Grade 3 } \\
\mathrm{n}(\%)\end{array}$ & $\begin{array}{c}\text { Grade 4 } \\
\mathrm{n}(\%)\end{array}$ & $\begin{array}{c}\text { Grade 5 } \\
\mathrm{n}(\%)\end{array}$ & $\begin{array}{c}\text { Grade1 } \\
\mathrm{n}(\%)\end{array}$ & $\begin{array}{c}\text { Garde 2 } \\
\mathrm{n}(\%)\end{array}$ & $\begin{array}{c}\text { Grade3 } \\
\mathrm{n}(\%)\end{array}$ & $\begin{array}{c}\text { Grade4 } \\
\mathrm{n}(\%)\end{array}$ & $\begin{array}{c}\text { Grade 5 } \\
\mathrm{n}(\%)\end{array}$ \\
\hline Hematologic & $4(7.5 \%)$ & $1(1.88 \%)$ & $3(5.6 \%)$ & $2(3.7 \%)$ & - & $3(11.1 \%)$ & $7(25.9 \%)$ & $8(29.6 \%)$ & - & - \\
\hline Gastrointestinal & $8(15 \%)$ & $5(9.4 \%)$ & $7(13.2 \%)$ & - & - & $2(7.4 \%)$ & $8(29.2 \%)$ & $2(7.4 \%)$ & $3(11.1 \%)$ & - \\
\hline Mucositis & $4(7.5 \%)$ & $2(3.7 \%)$ & $1(1.88 \%)$ & - & - & $5(18.5 \%)$ & $7(25.9 \%)$ & $4(14.8 \%)$ & $4(14.8 \%)$ & - \\
\hline $\begin{array}{l}\text { Asthenia/ } \\
\text { /anorexia }\end{array}$ & - & $2(3.7 \%)$ & - & - & - & $5(18.5 \%)$ & $6(22.2 \%)$ & $9(33.3 \%)$ & - & - \\
\hline Neuropathy & $1(1.88 \%)$ & $1(1.88 \%)$ & - & - & - & $1(3.7 \%)$ & $3(11.1 \%)$ & $1(3.7 \%)$ & - & - \\
\hline Infectious & - & $1(1.88 \%)$ & - & - & - & $1(3.7 \%)$ & $5(18.5 \%)$ & $4(14.8 \%)$ & - & - \\
\hline Renal & - & - & - & - & - & - & $4(14.8 \%)$ & - & - & - \\
\hline
\end{tabular}


Table 3. Comparative study of pattern of relapse*

\begin{tabular}{|c|c|c|c|c|}
\hline Site & $\begin{array}{c}\text { All patients } \\
\text { n (\%) }\end{array}$ & $\begin{array}{c}\text { CT group } \\
(n=27)\end{array}$ & $\begin{array}{l}\text { CTRT group } \\
(\mathrm{n}=53)\end{array}$ & $\mathbf{p}$ \\
\hline Overall recurrence & $34(42.5 \%)$ & $15(55.6 \%)$ & $19(35.8 \%)$ & 0.092 \\
\hline Locoregional recurrence & $16(20 \%)$ & $6(22.2 \%)$ & $10(18.9 \%)$ & 0.723 \\
\hline Distant recurrence & $29(36.3 \%)$ & $12(44.4 \%)$ & $17(32.1 \%)$ & 0.277 \\
\hline Peritoneal & $15(18.8 \%)$ & $10(37 \%)$ & $5(9.4 \%)$ & 0.003 \\
\hline Liver & $13(16.3 \%)$ & $6(22.2 \%)$ & $7(13.2 \%)$ & 0.301 \\
\hline Lung & $8(10 \%)$ & $1(3.7 \%)$ & $7(13.2 \%)$ & 0.255 \\
\hline Ovary & $2(2.5 \%)$ & $1(3.7 \%)$ & $1(1.9 \%)$ & 1 \\
\hline Bone & 1 (1.3\%) & $0 \%$ & $1(1.9 \%)$ & 1 \\
\hline
\end{tabular}

*Patients relapsed at multiple sites. The total number of recurrence sites was greater than the number of relapsed patients; CT — chemotherapy; CTRT — radio chemotherapy

cases followed by disease progression in $37.5 \%$ and lost of follow up in $12.8 \%$ of cases.

\section{Relapses and progression free survival}

The median follow-up was $38.48 \pm 28.67$ months (range, 4-139 months). Data of the first relapse only were recorded and categorized as loco-regional or distant (Tab. 3). After a mean follow-up of $18.85 \pm 15.60$ (3-75 months), recurrence occurred in $42.5 \%$ of patients within 22.5 months in the CTRT group and 14 months in the CT group $(\mathrm{p}=0.182)$. The overall rate of recurrence was higher in the CT group (55.6\%) compared to the CTRT group (35.8\%) without significant difference $(\mathrm{p}=0.092)$. The frequency of locoregional and distant relapses was higher in the CT group $(22.2 \%$ and $44.4 \%$, respectively) compared to the CTRT group (18.9\% and $32.1 \%$, respectively) without significant difference. Additionally, peritoneal recurrence was significantly higher in the CT group compared to the CTRT group ( $37 \%$ vs. 9.4\%, $\mathrm{p}=0.003$ ).

The 5-year PFS was $60.9 \%$ in the CTRT group and $36 \%$ in the CT group ( $\mathrm{p}=0.03$ ) (Fig. 1). Subgroup analyses were performed to identify patient populations who may benefit from CTRT (Tab. 4) showing that significant benefit from the addition of radiotherapy to adjuvant chemotherapy could not be excluded in women $(\mathrm{p}=0.008)$, patients under 70 years old $(\mathrm{p}=0.035)$, intestinal-type GC $(\mathrm{p}=0.032)$, moderately/poorly differentiated tumors $(\mathrm{p}=0.022)$ and positive LVI tumor $(\mathrm{p}=0.03)$ (Fig. 3). There also was a trend toward improved PFS with adjuvant CTRT in patients with advanced-stage III and IV ( $29.5 \%$ vs. $53.8 \%, \mathrm{p}=0.213)$ with increased outcomes especially in patients with pT3-T4 tumors (64\% vs. $35.6 \%, \mathrm{p}=0.051)$. In the

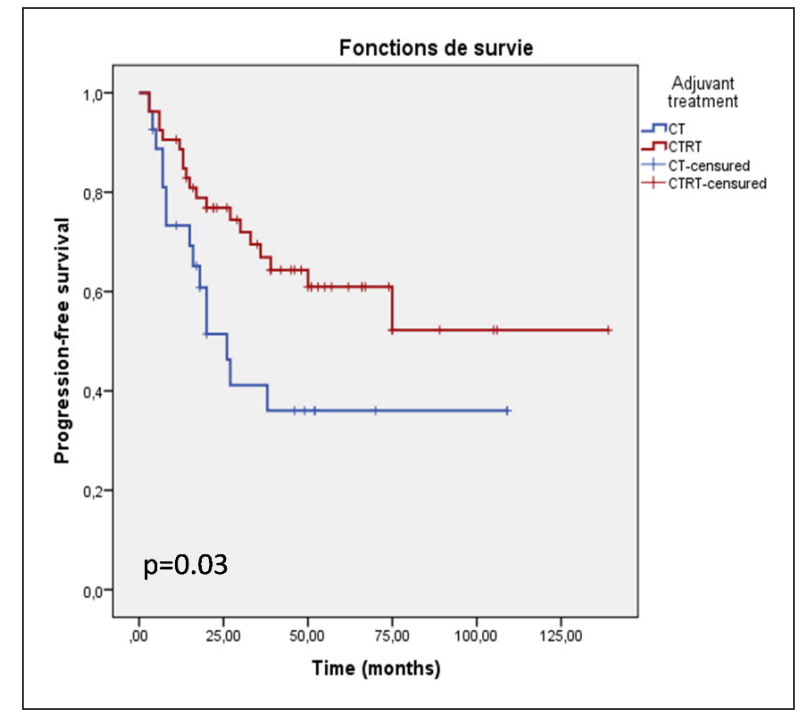

Figure 1. Kaplan-Meier survival curves of progression-free survival in all patients. There was a significant difference between adjuvant chemotherapy (CT) group and adjuvant radiochemotherapy (CTRT) $(p=0.03)$

73 patients with node-positive disease, 5-year PFS was slightly different (59.9\% in CTRT group vs. $36 \%$ in CT group, $\mathrm{p}=0.057$ ) (Fig. 2). Furthermore, the subgroup analysis demonstrated the superiority of adjuvant CTRT compared to CT in terms of PFS in patients classified pN2-N3 (57.8\%vs. $16.5 \%, \mathrm{p}=0.022)$ with a lymph node ratio greater than $25 \%(58.6 \%$ vs. $11.7 \%, \mathrm{p}=0.018)$. Moreover, we found that the benefit of adjuvant CTRT was statistically evident mainly for patients who had a D2 lymphadenectomy ( $56 \%$ vs. $28.4 \%, \mathrm{p}=0.01$ ). Nevertheless, it seems that in patients who did not have extended lymphadenectomy, the CTRT brings a gain of $19.5 \%$ on PFS at 5 years but also an obvious increase in PFS in patients whose number of 
Table 4. Univariate analysis of the 5 years progression-free survival (PFS)

\begin{tabular}{|c|c|c|c|c|}
\hline \multirow{2}{*}{ Variables } & & \multicolumn{2}{|c|}{5 years PFS } & \multirow{2}{*}{ P } \\
\hline & & CT ADJ & CTRT & \\
\hline \multicolumn{2}{|c|}{ All patients $(n=80)$} & $36 \%$ & $60.9 \%$ & 0.03 \\
\hline \multirow{2}{*}{ Gender } & Men & $51.4 \%$ & $59.3 \%$ & 0.671 \\
\hline & Women & $23.8 \%$ & $64.8 \%$ & 0.008 \\
\hline \multirow{2}{*}{ Age (years) } & $<70$ & $32.1 \%$ & $59.8 \%$ & 0.035 \\
\hline & $\geq 70$ & $47.6 \%$ & $65.5 \%$ & 0.440 \\
\hline \multirow{2}{*}{ ASA score } & ASA1-2 & $36.1 \%$ & $66.1 \%$ & 0.014 \\
\hline & ASA3 & $33.3 \%$ & $33.3 \%$ & 0.918 \\
\hline \multirow{2}{*}{ Weight Loss } & $<10 \%$ & $56.1 \%$ & $72.2 \%$ & 0.613 \\
\hline & $\geq 10 \%$ & $24.4 \%$ & $51.9 \%$ & 0.054 \\
\hline \multirow{2}{*}{ UICC stage } & $|-| \mid$ & $75 \%$ & $70.7 \%$ & 0.801 \\
\hline & III-IV & $29.5 \%$ & $53.8 \%$ & 0.213 \\
\hline \multirow{2}{*}{ pT stage } & pT1-T2 & $37.5 \%$ & $57.4 \%$ & 0.416 \\
\hline & pT3-T4 & $35.6 \%$ & $64 \%$ & 0,051 \\
\hline \multirow{2}{*}{$\mathrm{pN}$ stage } & N0-N1 & $72.8 \%$ & $16.5 \%$ & 0.919 \\
\hline & $\mathrm{N} 2-\mathrm{N} 3$ & $16.5 \%$ & $57.8 \%$ & 0.022 \\
\hline \multirow{2}{*}{ LN status } & $\mathrm{N}-$ & - & $66.7 \%$ & NA \\
\hline & $\mathrm{N}+$ & $36 \%$ & $59.9 \%$ & 0.057 \\
\hline \multirow{2}{*}{ LNR } & $\leq 25 \%$ & $61.4 \%$ & $64.1 \%$ & 0.708 \\
\hline & $>25 \%$ & $11.7 \%$ & $58.6 \%$ & 0.018 \\
\hline \multirow{2}{*}{ NRLN } & $<15 \mathrm{LN}$ & $21.4 \%$ & $77.8 \%$ & 0.056 \\
\hline & $\geq 15 \mathrm{LN}$ & $41.3 \%$ & $56.9 \%$ & 0.182 \\
\hline \multirow{2}{*}{ Resection } & TG & $38.1 \%$ & $70.2 \%$ & 0.077 \\
\hline & PG & $35.4 \%$ & $50.9 \%$ & 0.226 \\
\hline \multirow{2}{*}{ LND } & D1/D1.5 & $50.6 \%$ & $70.1 \%$ & 0.581 \\
\hline & D2 & $28.4 \%$ & $56.3 \%$ & 0.01 \\
\hline \multirow{2}{*}{ Tumor size [mm] } & $<50 \mathrm{~mm}$ & $37.4 \%$ & $84.4 \%$ & 0.016 \\
\hline & $\geq 50 \mathrm{~mm}$ & $33.3 \%$ & $45.1 \%$ & 0.324 \\
\hline \multirow{2}{*}{ Differentiation } & Well differentiated & $78.8 \%$ & $83 \%$ & 0.661 \\
\hline & Others & $0 \%$ & $30.1 \%$ & 0.022 \\
\hline \multirow{2}{*}{ Lauren type } & Intestinal & $37.8 \%$ & $68.8 \%$ & 0.032 \\
\hline & Mixed/diffuse & $30 \%$ & $33.8 \%$ & 0.568 \\
\hline \multirow{2}{*}{ LVI } & No & $88.9 \%$ & $86.7 \%$ & 0.828 \\
\hline & Yes & $0 \%$ & $20.6 \%$ & 0.03 \\
\hline \multirow{2}{*}{ PNI } & No & $88.9 \%$ & $90.1 \%$ & 0.930 \\
\hline & Yes & $0 \%$ & $13.5 \%$ & 0.076 \\
\hline
\end{tabular}

CT ADJ — adjuvant chemotherapy; CTRT — adjuvant radiochemotherapy; NRLN — number of retrieved lymph nodes; N- — no lymph node metastasis; $\mathrm{N}+$ - lymph node metastasis; LVI — lymphovascular invasion; PNI — perineural invasion

removed lymph nodes was less than $15(77.8 \% v s$. $21.4 \%, \mathrm{p}=0.056)$.

\section{Overall survival}

The 5-year overall survival was significantly higher in the CTRT group compared to the CT group (55.9\% vs. 33\%, $\mathrm{p}=0.015)$ (Fig. 5, Tab. 5). The subgroup analysis revealed that adjuvant CTRT resulted in an improved overall survival compared with adjuvant CT, especially in women $(\mathrm{p}=0.014)$, patients with ASA score under $3(\mathrm{p}=0.007)$, stage pT3-pT4 tumors (58.5\% vs. 34.4\%, p = 0.048), pa- 


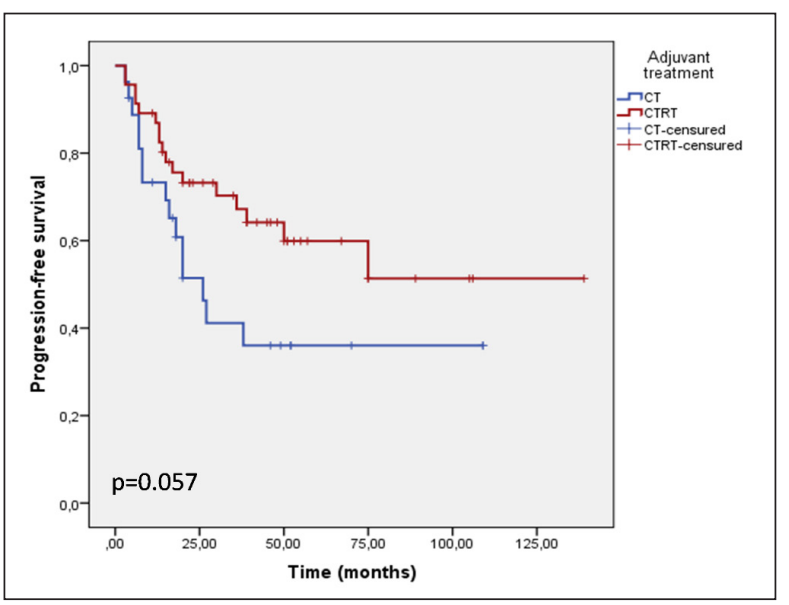

Figure 2. Kaplan-Meier survival curves of progression-free survival in lymph node-positive patients. There was a tendency to significant difference between adjuvant chemotherapy (CT) group and adjuvant radiochemotherapy (CTRT) $(p=0.057)$

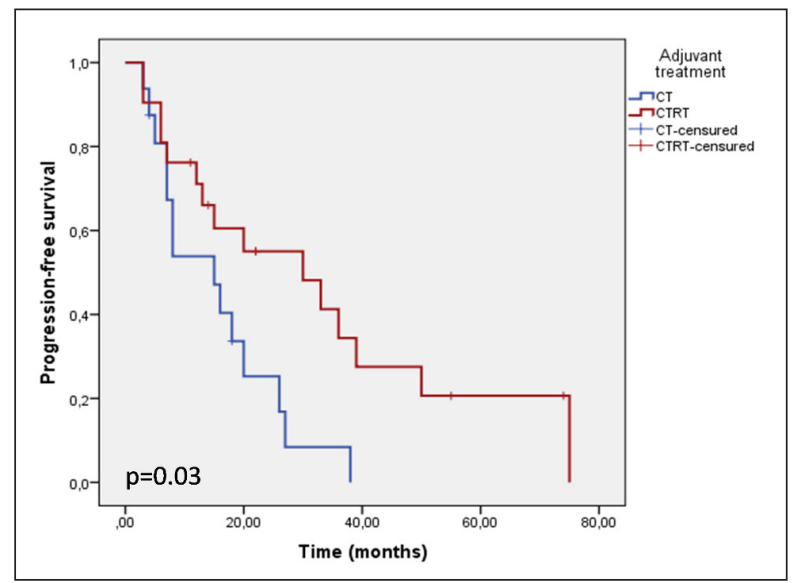

Figure 3. Kaplan-Meier survival curves of progression-free survival in LVI-positive patients. There was a significant difference between adjuvant chemotherapy (CT) group and adjuvant radiochemotherapy (CTRT) $(p=0.03)$

tients with lymph node metastasis (51.5\% vs. 33\%, $\mathrm{p}=0.046$ ) (Fig. 6) and particularly those with advanced $\mathrm{pN}$ stage $(\mathrm{p}=0.0078)$ and high lymph node ratio exceeding 25\% (49\% vs. 8.8\%, $\mathrm{p}=0.012$ ). Moreover, some histological criteria were associated with an improved overall survival with CTRT compared to adjuvant CT notably intestinal subtype $(\mathrm{p}=0.017)$, LVI positive tumors $(\mathrm{p}=0.006)$ (Fig. 7), PNI positive tumors ( $\mathrm{p}=0.027$ ) (Fig. 8). In the case of D2 lymphadenectomy, the benefit in terms of overall survival was higher in the adjuvant CTRT group compared to the adjuvant CT group (51.5\% vs. $29.4 \%, \mathrm{p}=0.008)$ on the other hand,

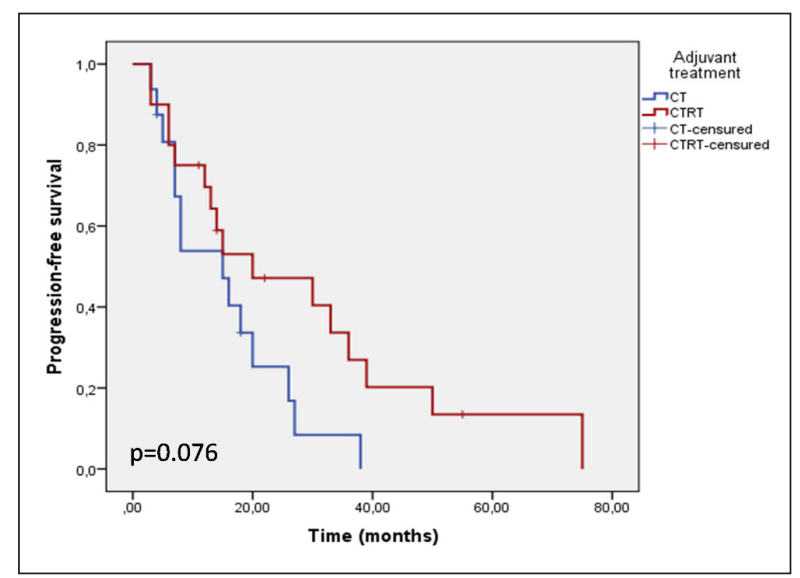

Figure 4. Kaplan-Meier survival curves of progression-free survival in PNI-positive patients. There was a significant difference between adjuvant chemotherapy (CT) group and adjuvant radiochemotherapy (CTRT) $(p=0.076)$

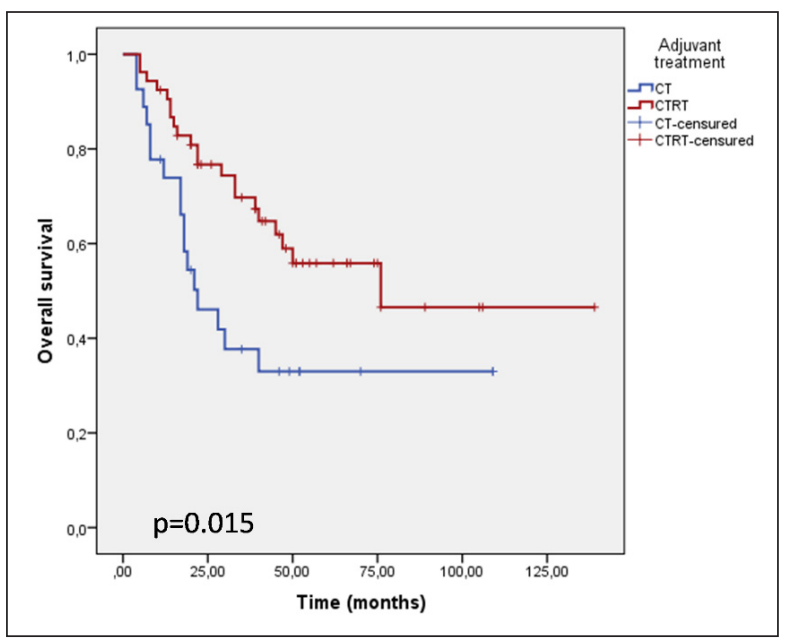

Figure 5. Kaplan-Meier survival curves of overall survival in all patients. There was a significant difference between adjuvant chemotherapy (CT) group and adjuvant radiochemotherapy (CTRT) $(p=0.015)$

there was no significant difference between the two groups in the event of D1-D1.5 lymphadenectomy with a gain of $20.9 \%$ in terms of OS at 5 years in the CTRT group. Also, the adjuvant CTRT allowed a $47.7 \%$ increase in the overall survival of patients whose number of lymph nodes removed was less than 15 compared to the adjuvant CT $(\mathrm{p}=0.07)$.

\section{Discussion}

Despite the advancement in adjuvant and neoadjuvant therapy, the 5-year survival rate for patients with positive lymph node gastric cancer is as low 
Table 5. Univariate analysis of the 5 years overall survival (OS)

\begin{tabular}{|c|c|c|c|c|}
\hline \multirow{2}{*}{ Variables } & & \multicolumn{2}{|c|}{5 years OS } & \multirow{2}{*}{ p } \\
\hline & & CT ADJ & CTRT & \\
\hline \multicolumn{2}{|l|}{ All patient $(n=80)$} & $33 \%$ & $55.9 \%$ & 0.015 \\
\hline \multirow{2}{*}{ Gender } & Men & $43.1 \%$ & $54.7 \%$ & 0.300 \\
\hline & Women & $23.6 \%$ & $58.9 \%$ & 0.014 \\
\hline \multirow{2}{*}{ Age (years) } & $<70$ & $31 \%$ & $59.2 \%$ & 0.033 \\
\hline & $\geq 70$ & $37.5 \%$ & $40.4 \%$ & 0.304 \\
\hline \multirow{2}{*}{ ASA score } & ASA1-2 & $32.9 \%$ & $60.7 \%$ & 0.007 \\
\hline & ASA3 & $33.3 \%$ & $25 \%$ & 0.976 \\
\hline \multirow{2}{*}{ Weight Loss } & $<10 \%$ & $42.4 \%$ & $64.4 \%$ & 0.230 \\
\hline & $\geq 10 \%$ & $29.6 \%$ & $43.9 \%$ & 0.131 \\
\hline \multirow{2}{*}{ UICC stage } & $|-| \mid$ & $50 \%$ & $70.9 \%$ & 0.176 \\
\hline & III-IV & $29.3 \%$ & $42.8 \%$ & 0.260 \\
\hline \multirow{2}{*}{ pT stage } & pT1-T2 & $25 \%$ & $51.4 \%$ & 0.112 \\
\hline & pT3-T4 & $34.4 \%$ & $58.5 \%$ & 0.048 \\
\hline \multirow{2}{*}{$\mathrm{pN}$ stage } & N0-N1 & $75 \%$ & $69.1 \%$ & 0.948 \\
\hline & $\mathrm{N} 2-\mathrm{N} 3$ & $13 \%$ & $48.8 \%$ & 0.007 \\
\hline \multirow{2}{*}{ LN status } & $\mathrm{N}-$ & - & $83.3 \%$ & NA \\
\hline & $\mathrm{N}+$ & $33 \%$ & $51.5 \%$ & 0.046 \\
\hline \multirow{2}{*}{ LNR } & $\leq 25 \%$ & $57.1 \%$ & $62.7 \%$ & 0.437 \\
\hline & $>25 \%$ & $8.8 \%$ & $49 \%$ & 0.012 \\
\hline \multirow{2}{*}{ NRLN } & $<15 \mathrm{LN}$ & $19 \%$ & $66.7 \%$ & 0.07 \\
\hline & $\geq 15 \mathrm{LN}$ & $36.6 \%$ & $53.1 \%$ & 0.08 \\
\hline \multirow{2}{*}{ Resection } & TG & $28 \%$ & $64.5 \%$ & 0.016 \\
\hline & PG & $39 \%$ & $47.4 \%$ & 0.277 \\
\hline \multirow{2}{*}{ LND } & D1/D1.5 & $42.2 \%$ & $63.1 \%$ & 0.472 \\
\hline & D2 & $29.4 \%$ & $51.5 \%$ & 0.008 \\
\hline \multirow{2}{*}{ Tumor size [mm] } & $<50 \mathrm{~mm}$ & $33.3 \%$ & $84.7 \%$ & 0.002 \\
\hline & $\geq 50 \mathrm{~mm}$ & $33.3 \%$ & $36.9 \%$ & 0.471 \\
\hline \multirow{2}{*}{ Differentiation } & Well differentiated & $79.5 \%$ & $77.2 \%$ & 0.858 \\
\hline & Others & $0 \%$ & $29 \%$ & 0.007 \\
\hline \multirow{2}{*}{ Lauren type } & Intestinal & $33.8 \%$ & $62.2 \%$ & 0.017 \\
\hline & Mixed/diffuse & $30 \%$ & $32.6 \%$ & 0.483 \\
\hline \multirow{2}{*}{ LVI } & No & $90 \%$ & $76.9 \%$ & 0.507 \\
\hline & Yes & $0 \%$ & $23.7 \%$ & 0.006 \\
\hline \multirow{2}{*}{ PNI } & No & $90 \%$ & $8.3 \%$ & 0.659 \\
\hline & Yes & $0 \%$ & $16.3 \%$ & 0.027 \\
\hline
\end{tabular}

CT ADJ — adjuvant chemotherapy; CTRT — adjuvant radiochemotherapy; NRLN — number of retrieved lymph nodes; N- — no lymph node metastasis; $\mathrm{N}+$ - lymph node metastasis; LVI — lymphovascular invasion; PNI- perineural invasion

as $15-20 \%$, and even node-negative patients have a 5-year survival rate of $45-55 \%$ in the case of advanced $\mathrm{T}$ stage (T3-T4N0) [18] with recurrence rates ranging from $20 \%$ to $40 \%$ within 2 years after complete resections depending on specific factors such as the initial stage of the disease, proximal location and Lauren's histological type [19]. These data justify the need for an adapted or even intensified adjuvant therapeutic strategy to reduce the relapse rate depending on these prognostic factors. Although the role of adjuvant chemotherapy (CT) has been established and adjuvant CT is routinely 


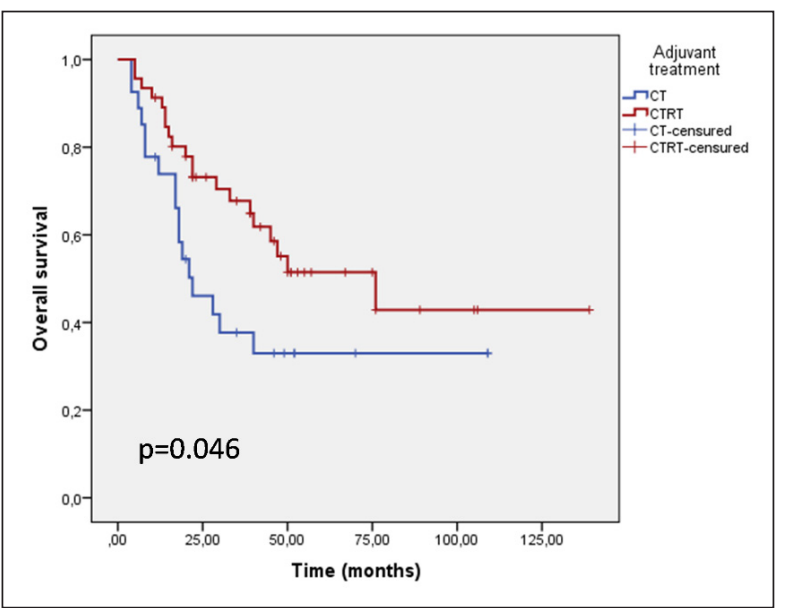

Figure 6. Kaplan-Meier survival curves of overall survival in lymp node-positive patients. There was a significant difference between adjuvant chemotherapy (CT) group and adjuvant radiochemotherapy (CTRT) $(p=0.046)$

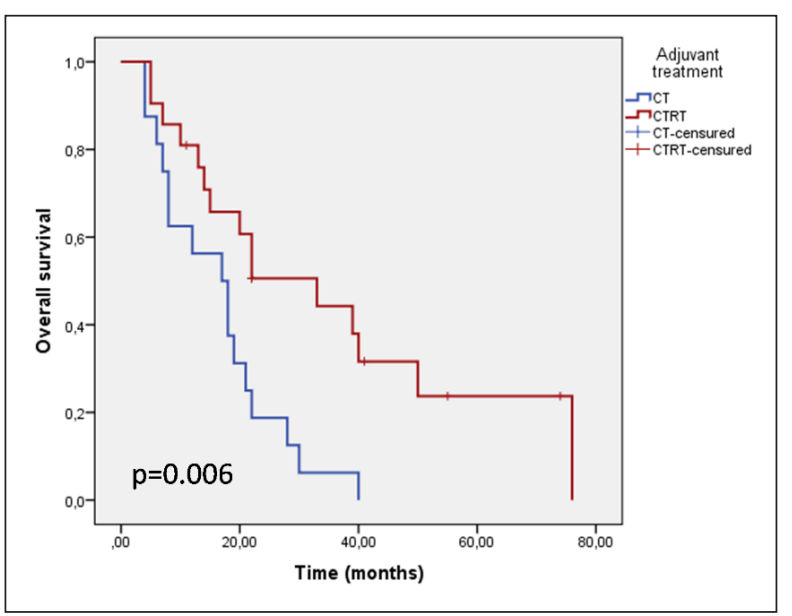

Figure 7. Kaplan-Meier survival curves of overall survival in patient with LVI positive tumors. There was a significant difference between adjuvant chemotherapy (CT) group and adjuvant radiochemotherapy (CTRT) $(p=0.006)$

used for D2-dissected gastric cancer, the value of combining postoperative RT with CT is still largely debated. Our study suggested the superiority of adjuvant CTRT to adjuvant CT not only in terms of reducing the risk of overall recurrence but also in improving the 5-year OS, especially in patients with lymph node metastasis, high LNR and lymphovascular and perineural invasion which is the most interesting feature. Moreover, based on the literature data, we aimed to identify selection criteria to propose intensive adjuvant treatment for a subgroup of patients presenting conventional pejorative prognostic factors of survival. These results

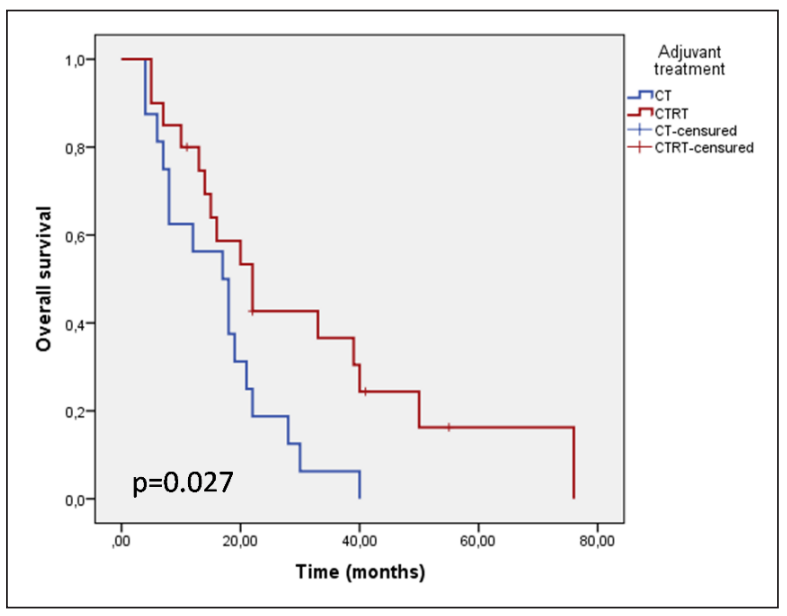

Figure 8. Kaplan-Meier survival curves of overall survival in patient with PNI positive tumors. There was a significant difference between adjuvant chemotherapy (CT) group and adjuvant radiochemotherapy (CTRT) $(p=0.027)$

were consistent with data from the literature regarding the prognostic impact of CTRT on recurrence. However, it seems that our study is distinguished by encouraging results in favor of CTRT in improving overall survival ( $55.9 \%$ vs. $33 \%$; $\mathrm{p}=0.015)$.

Very few studies have compared adjuvant CT with adjuvant CTRT and most of them did not show a significant improvement of overall survival by associating RT to CT despite the gain in terms of recurrence survival. The ARTIST trial was the first phase III study that compared the adjuvant treatment with chemotherapy ( 6 cycles of XP - capecitabine and cisplatin) in 172 patients $v s$. the association of chemotherapy and radiotherapy (2 cycles of XP $+\mathrm{XP}$ and radiotherapy +2 more cycles of XP) in 188 patients after D2-lymphadenectomy [20]. The addition of XRT to XP chemotherapy did not significantly prolong the 3 -year disease-free survival (DFS) $(78.2 \%$ vs. $74.2 \%$; $\mathrm{p}=0.862)$. Moreover, in the updating of their results after 7 years of follow-up, DFS remained similar between treatment arms $(\mathrm{HR}=0.740$; 95\% CI $=0.520-1.050$; $\mathrm{p}=0.0922)$, OS was also similar $(\mathrm{HR}=1.130 ; 95 \%$ $\mathrm{CI}=0.775-1.647 ; \mathrm{p}=0.5272)$ but the addition of radiotherapy provided an improvement in disease-free survival for node-positive patients [11]. In a South Korean phase III study of Kim et al, 90 patients having had R0 surgery with D2 dissection were randomized between two arms: an adjuvant CT arm (44 patients) and an adjuvant CTRT arm (46 patients) [21]. In this study, although five-year 
disease-free survival (DFS), which was the primary endpoint of this trial, was not significantly improved in the combined modality, locoregional recurrence-free survival (LRRFS) (93.2\% vs. 66.8\%, $\mathrm{p}=0.014)$ and metastatic recurrence-free survival (73.5\% vs. $54.6 \%, \mathrm{p}=0.056)$ were improved. In contrast to these two trials, a significant benefit in 5-year RFS (45.2\% vs. 35.8; $\mathrm{p}=0.012)$, but not in OS, was shown in a Chinese multicenter randomized trial in which patients with D2-dissection were randomly assigned to chemotherapy alone (165 patients) or intensity-modulated RT plus concurrent chemotherapy (IMRT-C) (186 patients) [22]. In this study, the IMRT-C was associated with an increase in the median duration of RFS compared to chemotherapy (50 months vs. 32 months) and the hazard ratio for recurrence was 1.35 (95\% CI: $1.03-1.78 ; \mathrm{p}=0.029$ ). These data support our results as we found significant improvement in PFS at 5 years $(60.9 \%$ vs. $36 \%, \mathrm{p}=0.03)$ with adjuvant radiochemotherapy compared to adjuvant CT.

The analysis of the patterns of recurrence of our patients revealed that locoregional and distant relapses were more frequent in the adjuvant CT group than in the CTRT group without a significant statistical difference, which is in line with the results of the ARTIST trial where locoregional relapse was more frequent in the XP arm (13\%) than in the XPRT arm (7\%; $\mathrm{p}=0.033)$ and distant metastases were observed in $27 \%$ and $24 \%$ of patients in the XP and XPRT arms, respectively $(p=0.5568)$ [11]. Moreover, in the randomized study of Zhu et al. the rate of distant metastasis was slightly higher in the chemotherapy group $(26.7 \%$ vs. $24.2 \%, \mathrm{p}=0.595)[22]$.

The meta analysis of the results of the two randomized controlled trials from South Korea [20, 21] and the study of China [22] comparing adjuvant chemotherapy and CRT, which included a total of 895 patients, showed that postoperative CTRT significantly improved locoregional recurrence-free survival $(\mathrm{HR}=0.53,95 \% \mathrm{CI}=0.32-0.87$, $\mathrm{p}=0.01)$ and disease-free survival $(\mathrm{HR}=0.72,95 \%$ $\mathrm{CI}=0.59-0.89, \mathrm{p}=0.002)$; without a significant improvement of distant metastasis recurrence-free survival $(\mathrm{HR}=0.86 ; 95 \% \mathrm{CI}=0.66-1.11 ; \mathrm{p}=0.25)$ and overall survival $(\mathrm{HR}=0.79,95 \% \mathrm{CI}=0.61-1.03$, $\mathrm{p}=0.08)[10]$.

In our study, the analysis of subgroups according to the extent of lymphadenectomy had demonstrat- ed the superiority of CTRT to CT as an adjuvant treatment to D2 lymphadenectomy both in terms of OS and PFS. In the group of patients with less extensive lymphadenectomy, CTRT offered a better OS (19\% vs. 66.7\%) and PFS (21.4\% vs. $77.8 \%)$ without significant difference. This last observation agrees with the data from the SWOG/INT-0116 trial where the CTRT improved the oncological results of all patients who had mostly had D0-D1 dissection [23]. Paradoxically, Dikken et al. had retrospectively compared survival and recurrence patterns of 91 patients in phase I and II studies evaluating more intensified postoperative CRT with 694 patients from the Dutch Gastric Cancer Group Trial (DGCT) that randomly assigned patients between D1 and D2 lymphadenectomy and suggested that the addition of CTRT seemed to be beneficial in preventing local recurrence after D1-dissection, but not after D2-dissection [24].

Consequently, the role of adjuvant RT remains unclear after an adequate lymphadenectomy but it seems that the identification of a high-risk subgroup for loco-regional recurrence among D2-dissected patients is essential and of higher priority than assessing the efficacy of a regular application of adjuvant CRT in all D2-dissected gastric cancer patients [25].

Regardless of the type of lymphadenectomy, the lymph node status remains largely involved in the therapeutic indications since it represents a prognostic factor determining survival and recurrence $[26,27]$. In fact, in our study, the adjuvant CTRT allowed a significant improvement in the overall 5 -year survival of patients with lymph node involvement $(\mathrm{p}=0.046)$, with a tendency to better progression-free survival $(\mathrm{p}=0.057)$. These data appear to be consistent with those of the ARTIST trial where the subgroup analysis of 396 patients with node-positive disease revealed that the 3 -year DFS was significantly improved in the XPRT arm compared to the XP arm ( $76 \% v$ s. $72 \%$ in XPRT arm; $p=0.04$ ) and found that in patients without lymph node involvement, chemotherapy would be more beneficial than CTRT in terms of DFS $(\mathrm{HR}=1.359,95 \% \mathrm{CI}=0.477-3.876)$ with no significant difference [11]. Moreover, we have found that the benefit provided by the adjuvant CTRT in terms of OS ( $13 \%$ vs. $48.8 \%, \mathrm{p}=0.0078)$, but especially in terms of PFS ( $16.5 \%$ vs. $57.8 \%, \mathrm{p}=0.022)$, was significantly higher than the adjuvant CT, es- 
pecially in patients with more advanced $\mathrm{pN}$ stages (pN2-pN3). This is consistent with the Korean report of Chang et al. which revealed that N3 patients are at substantial risk of regional recurrence as well as peritoneal and distant spread despite D2 dissection and adjuvant chemotherapy suggesting that an intensified treatment by chemoradiotherapy would improve survival outcomes [28].

As lymph node ratio (LNR) was previously identified as an independent prognostic factor after D1 and D2 lymph node dissections [29, 30], we compared the prognostic impact of adjuvant CTRT to that of adjuvant CT according to the lymph node ratio. This subgroup analysis had demonstrated that, unlike patients whose LNR was less than 25\%, those whose lymph node ratio was greater than $25 \%$ and treated with adjuvant CTRT had a significant gain of $40.2 \%$ in terms of OS at 5 years and $46.9 \%$ in terms of PFS at 5 years compared to patients who received adjuvant CT. These findings are consistent with the results of the subgroup analysis of the ARTIST trial were the effect of radiotherapy in patients with a high lymph node ratio $(\geq 0.083)$ was different from the effect in patients with a low lymph node ratio in both DFS $(\mathrm{HR}=2.03$; 95\% CI $=1.44-2.87 ; \mathrm{p}<0.01)$ and overall survival $(\mathrm{HR}=1.98 ; 95 \% \mathrm{CI}=1.38-2.83 ; \mathrm{p}<0.01)$ suggesting that the lymph node ratio might represent an absolute, reproducible factor that could help select patients for CTRT [11]. On the other hand, the integration of the notion of the lymph node ratio during the evaluation of the prognostic contribution of adjuvant CTRT was mentioned in the retrospective study by Costa et al. [31]. Indeed, this study included 142 patients (90 patients treated with surgery only and 52 patients treated with resection followed by adjuvant CTRT) classified according to the LNR (NR0 $=0 \%$, NR $1=1-9 \%$, NR2 $=10-25 \%$, NR3 $>25 \%)$ and concluded that the individuals with a lower LNR had no benefit with adjuvant CTRT both in OS $(78.8 \%$ vs. $76.9 \%)$ and DFS ( $81.8 \%$ vs. $76.9 \%)$, whereas those with a higher LNR treated by CTRT had a significant improvement in OS $(71.4 \%$ vs. $30.9 \%$; $\mathrm{p}=0.038)$ and superior but not statistically significant gain regarding DFS ( $48.9 \%$ vs. $30.3 \%$; $\mathrm{p}=0.145)$. In view of these data, it seems that lymph node involvement represents a decisive element in favor of the intensification of the adjuvant treatment of locally advanced gastric cancers by associating radiotherapy with chemotherapy, which represents the rationale of the ongoing ARTIST II trial aiming to evaluate the benefit of adjuvant combined therapy only in $\mathrm{pN}+$ patients.

Depth of parietal invasion has long been considered an independent factor for survival and recurrence in gastric cancer [32-34] and authors consider this parameter as a determining factor of the delay of relapses. In fact, in the study by Otsuji [35], the depth of parietal infiltration represents an independent factor determining the time to recurrence with a median time of 11.7 months in the T4 stages, and 15.5 months in the pT3 stages, 22.2 months in pT2 stages, and 39.5 months in pT1 stages without forgetting that lymph node involvement is significantly correlated with the depth of parietal invasion. Based on these data, we suggest a combined strategy for T3-T4 tumors as we found that in this group of patients the benefit provided by CTRT compared to CT both in terms of OS (34.4\% vs. 58.5\%; $\mathrm{p}=0.048)$ and PFS $(35.6 \%$ vs. $64 \% ; \mathrm{p}=0.051)$ is superior. Whereas in the case of earlier tumors the two strategies remain comparable.

Moreover, as PNI and LVI have been investigated as prognostic factors of recurrence and overall survival in resected gastric cancer [36, 37], we found that CTRT provided better overall survival rates and lower recurrence in the subgroup of patients with PNI and LVI compared to adjuvant chemotherapy and this significant difference was not reported in cases of PNI and LVI negative tumors. Our findings are similar to those reported by Yu et al. who evaluated the influence of adjuvant RT on recurrence at each locoregional subsite, and investigated which subgroups received the most benefit by comparing failure patterns between CCRT and chemotherapy groups of the ARTIST trial [38]. In this study, the authors used Forest plots to represent locoregional recurrence-free survival (LRRFS) HRs and 95\% CIs and demonstrated that patients with lymphovascular invasion $(\mathrm{HR}=0.45,95 \%$ $\mathrm{CI}=0.22-0.90, \mathrm{p}=0.02)$ showed greater LRRFS benefit from XPRT than XP. It is therefore wise to consider that these two histological data would be helpful to select patients for an intensified treatment with radiotherapy as suggested by the review of Agolli et al. [39].

In addition, the results of our study agree with those of the Mac Donald trial suggesting that post- 
operative CTRT would be more effective in the intestinal type [16]. The ARTIST trial also demonstrated that the effect of the addition of radiotherapy on DFS and OS differed by Lauren classification (interaction $\mathrm{p}=0.04$ for PFS; interaction $\mathrm{p}=0.03$ for OS). The Forest plot of HRs and 95\% CIs for disease-free survival revealed that the effect of radiotherapy in patients with intestinal-type GC (HR $=0.442,95 \% \mathrm{CI}=0.231-0.845)$ was different from the effect in patients with diffuse GC $(\mathrm{HR}=0.826,95 \% \mathrm{CI}=0.543-1.255)[11]$.

And, finally, in 2016, in the CRITICS study, 788 patients were randomized after preoperative chemotherapy with ECX or EOX and surgery between a group of postoperative chemotherapy (393 patients) and a group of postoperative radiochemotherapy (395 patients) [40]. This international study showed the absence of difference in terms of OS between the two groups ( $41.3 \%$ in the CT adj arm and $40.9 \%$ in the CTRT adj arm, $\mathrm{p}=0.99$ ) with different profiles of toxicity: higher grade III hematological toxicity in the adj CT arm ( $44 \%$ vs. $34 \%$; $\mathrm{p}=0.01)$ and higher grade III gastrointestinal toxicity in the CTRT arm ( $37 \%$ vs. $42 \%$; $\mathrm{p}=0.14)$, which is in line with our results where the rate of grade 3-4 gastrointestinal toxicity was $22.6 \%$ in the CTRT group and $18.5 \%$ in the CT group and the rate of grade 3-4 hematological toxicity was higher in the CT group (29.6\%) than in the CTRT group (9.3\%). Moreover, most comparative studies have shown no increase in grade 3-4 treatment-related toxicity in the CTRT group with modern RT techniques (IMRT or CT-based 3D-CRT) compared with the chemotherapy alone group [10].

However, our study has certain limitations. Indeed, this is a retrospective monocentric study including a small number of patients with variable CT regimens, which leads to a higher risk of selection bias. Furthermore, there was a different stage distribution between the two groups, with more stage III patients in the CT group than in the CRT group $(70.4 \%$ vs. $52.8 \%$; $\mathrm{p}=0.014)$, which reflects the attitude adopted in our institution favoring an aggressive systemic treatment strategy for locally advanced tumors likely to present a higher risk of metastatic recurrence rather than locoregional recurrence. This high rate of stage III in the CT group did not translate into a statistically significant difference in terms of survival and CTRT was still superior to adjuvant CT. In addition, our study included patients whose lymphadenectomy was not extensive with a rate of D1-lymphadenectomy of $8.8 \%$ and a number of LN lower than 15 in $20 \%$ of the cases. However, our results remain interpretable since the interest of an extended lymphadenectomy remains a subject of controversy in the area of adjuvant therapies and new techniques of irradiation taking into account the morbidity associated with lymph node surgery reported in the majority of randomized studies.

\section{Conclusion}

Even if there are no strict recommendations concerning the intensification of the adjuvant treatment of locally advanced gastric cancers by associating radiotherapy with chemotherapy, the indication of this combined approach should take into account the prognostic factors that have a significant impact on recurrence and survival outcomes to select patients who can benefit from this approach, especially those with lymph node involvement, high LNR LVI, and PNI.

\section{Conflicts of interest}

The authors declare no conflicts of interest.

\section{Funding}

The author(s) received no financial support for the research, authorship, and/or publication of this article.

\section{Ethics approval}

The ethics review board approved this study and did not require informed consent from study participants since this was a strictly registry-based study.

\section{References}

1. Siegel RL, Miller KD, Fuchs $H E$, et al. Cancer statistics, 2015. CA Cancer J Clin. 2015; 65(1): 5-29, doi: 10.3322/ caac.21254, indexed in Pubmed: 25559415.

2. McCulloch P, Nita ME, Kazi H, et al. Extended versus limited lymph nodes dissection technique for adenocarcinoma of the stomach. Cochrane Database Syst Rev. 2004(4): CD001964, doi: 10.1002/14651858.CD001964.pub2, indexed in Pubmed: 15495024

3. Gunderson L. Gastric cancer - patterns of relapse after surgical resection. Seminars in Radiation Oncology. 2002; 12(2): 150-161, doi: 10.1053/srao.2002.30817, indexed in Pubmed: 11979416. 
4. Landry J, Tepper J, Wood W, et al. Patterns of failure following curative resection of gastric carcinoma. Int J Radiat Oncol Biol Phys. 1990; 19(6): 1357-1362, doi: 10.1016/03603016(90)90344-j.

5. Macdonald JS, Smalley SR, Benedetti J, et al. Chemoradiotherapy after surgery compared with surgery alone for adenocarcinoma of the stomach or gastroesophageal junction. N Engl J Med. 2001; 345(10): 725-730, doi: 10.1056/ NEJMoa010187, indexed in Pubmed: 11547741.

6. Panzini I, Gianni L, Fattori PP, et al. Adjuvant chemotherapy in gastric cancer: a meta-analysis of randomized trials and a comparison with previous meta-analyses. Tumori. 2002; 88(1): 21-27, indexed in Pubmed: 12004845.

7. Mari E, Floriani I, Tinazzi A, et al. Efficacy of adjuvant chemotherapy after curative resection for gastric cancer: a meta-analysis of published randomised trials. A study of the GISCAD (Gruppo Italiano per lo Studio dei Carcinomi dell'Apparato Digerente). Ann Oncol. 2000; 11(7): 837-843, doi: 10.1023/a:1008377101672, indexed in Pubmed: 10997811.

8. Janunger KG, Hafström L, Glimelius B. Chemotherapy in gastric cancer: a review and updated meta-analysis. Eur J Surg. 2002; 168(11): 597-608, doi: $10.1080 / 11024150201680005$, indexed in Pubmed: 12699095.

9. Sakuramoto S, Sasako M, Yamaguchi T, et al. ACTS-GC Group. Adjuvant chemotherapy for gastric cancer with S-1, an oral fluoropyrimidine. N Engl J Med. 2007; 357(18): 1810-1820, doi: 10.1056/NEJMoa072252, indexed in Pubmed: 17978289.

10. Huang YY, Yang Q, Zhou SW, et al. Postoperative chemoradiotherapy versus postoperative chemotherapy for completely resected gastric cancer with D2 Lymphadenectomy: a meta-analysis. PLoS One. 2013; 8(7): e68939, doi: 10.1371/journal.pone.0068939, indexed in Pubmed: 23874819.

11. Park SeH, Sohn TS, Lee J, et al. Phase III Trial to Compare Adjuvant Chemotherapy With Capecitabine and Cisplatin Versus Concurrent Chemoradiotherapy in Gastric Cancer: Final Report of the Adjuvant Chemoradiotherapy in Stomach Tumors Trial, Including Survival and Subset Analyses. J Clin Oncol. 2015; 33(28): 3130-3136, doi: 10.1200/JCO.2014.58.3930, indexed in Pubmed: 25559811.

12. Hamilton SR, Aaltonen LA. Pathology and genetics of tumours of the digestive system. Vol. 48. IARC Press, Lyon 2000.

13. Japanese Gastric Cancer Association. Japanese Classification of Gastric Carcinoma — 2nd English Edition. Gastric Cancer. 1998; 1(1): 10-24, doi: 10.1007/s101200050051, indexed in Pubmed: 11957040.

14. Japanese Gastric Cancer Association. Japanese gastric cancer treatment guidelines 2010 (ver. 3). Gastric Cancer. 2011; 14(2): 113-123, doi: 10.1007/s10120-011-0042-4, indexed in Pubmed: 21573742.

15. Japanese Gastric Cancer Association. Gastric cancer treatment guidelines in Japan (ver. 4). Gastric Cancer. 2014; 20(1): 1-19, doi: 10.1007/s10120-016-0622-4, indexed in Pubmed: 27342689.

16. Smalley SR, Benedetti JK, Haller DG, et al. Updated analysis of SWOG-directed intergroup study 0116: a phase III trial of adjuvant radiochemotherapy versus observation after curative gastric cancer resection. J Clin Oncol. 2012;
30(19): 2327-2333, doi: 10.1200/JCO.2011.36.7136, indexed in Pubmed: 22585691.

17. National Institutes of Health. Common terminology criteria for adverse events (CTCAE) version 4. NIH 2009.

18. Bockbrader M, Kim E. Role of intensity-modulated radiation therapy in gastrointestinal cancer. Expert Rev Anticancer Ther. 2009; 9(5): 637-647, doi: 10.1586/era.09.16, indexed in Pubmed: 19445580.

19. D'Angelica M, Gonen M, Brennan MF, et al. Patterns of initial recurrence in completely resected gastric adenocarcinoma. Ann Surg. 2004; 240(5): 808-816, doi: 10.1097/01. sla.0000143245.28656.15, indexed in Pubmed: 15492562.

20. Lee J, Lim DoH, Kim S, et al. Phase III trial comparing capecitabine plus cisplatin versus capecitabine plus cisplatin with concurrent capecitabine radiotherapy in completely resected gastric cancer with D2 lymph node dissection: the ARTIST trial. J Clin Oncol. 2012; 30(3): 268-273, doi: 10.1200/JCO.2011.39.1953, indexed in Pubmed: 22184384.

21. Kim TH, Park SR, Ryu KW, et al. Phase 3 trial of postoperative chemotherapy alone versus chemoradiation therapy in stage III-IV gastric cancer treated with RO gastrectomy and D2 lymph node dissection. Int J Radiat Oncol Biol Phys. 2012; 84(5): e585-e592, doi: 10.1016/j. ijrobp.2012.07.2378, indexed in Pubmed: 22975616.

22. Zhu Wg, Xua Df, Pu J, et al. A randomized, controlled, multicenter study comparing intensity-modulated radiotherapy plus concurrent chemotherapy with chemotherapy alone in gastric cancer patients with $D 2$ resection. Radiother Oncol. 2012; 104(3): 361-366, doi: 10.1016/j. radonc.2012.08.024, indexed in Pubmed: 22985776.

23. HundahI SA, Macdonald JS, Benedetti J, et al. Southwest Oncology Group and the Gastric Intergroup. Surgical treatment variation in a prospective, randomized trial of chemoradiotherapy in gastric cancer: the effect of undertreatment. Ann Surg Oncol. 2002; 9(3): 278-286, doi: 10.1007/BF02573066, indexed in Pubmed: 11923135.

24. Dikken JL, Jansen EPM, Cats A, et al. Impact of the extent of surgery and postoperative chemoradiotherapy on recurrence patterns in gastric cancer. J Clin Oncol. 2010; 28(14): 2430-2436, doi: 10.1200/JCO.2009.26.9654, indexed in Pubmed: 20368551.

25. Chang JS, Koom WS, Lee Y, et al. Postoperative adjuvant chemoradiotherapy in D2-dissected gastric cancer: is radiotherapy necessary after D2-dissection? World J Gastroenterol. 2014; 20(36): 12900-12907, doi: 10.3748/wjg. v20.i36.12900, indexed in Pubmed: 25278687.

26. Kattan MW, Karpeh MS, Mazumdar M, et al. Postoperative nomogram for disease-specific survival after an R0 resection for gastric carcinoma. J Clin Oncol. 2003; 21(19): 3647-3650, doi: 10.1200/JCO.2003.01.240, indexed in Pubmed: 14512396.

27. Chen D, Jiang B, Xing J, et al. Validation of the memorial Sloan-Kettering Cancer Center nomogram to predict disease-specific survival after $\mathrm{R} 0$ resection in a Chinese gastric cancer population. PLoS One. 2013; 8(10): e76041, doi: 10.1371/journal.pone.0076041, indexed in Pubmed: 24146811.

28. Chang JS, Lim JS, Noh SH, et al. Patterns of regional recurrence after curative D2 resection for stage III (N3) gastric cancer: implications for postoperative radiotherapy. Radiother Oncol. 2012; 104(3): 367-373, doi: 10.1016/j. radonc.2012.08.017, indexed in Pubmed: 22981610. 
29. Marchet A, Mocellin S, Ambrosi A, et al. Italian Research Group for Gastric Cancer (IRGGC). The ratio between metastatic and examined lymph nodes ( $\mathrm{N}$ ratio) is an independent prognostic factor in gastric cancer regardless of the type of lymphadenectomy: results from an Italian multicentric study in 1853 patients. Ann Surg. 2007; 245(4): 543-552, doi: 10.1097/01.sla.0000250423.43436. e1, indexed in Pubmed:17414602.

30. Lee SY, Hwang I, Park YS, et al. Metastatic lymph node ratio in advanced gastric carcinoma: a better prognostic factor than number of metastatic lymph nodes? Int J Oncol. 2010; 36(6): 1461-1467, doi: 10.3892/ijo_00000632, indexed in Pubmed: 20428770.

31. Costa WL, Coimbra FJF, Fogaroli RC, et al. Adjuvant chemoradiotherapy after d2-lymphadenectomy for gastric cancer: the role of $\mathrm{n}$-ratio in patient selection. results of a single cancer center. Radiat Oncol. 2012; 7: 169, doi: 10.1186/1748-717X-7-169, indexed in Pubmed: 23068190.

32. Kim JP, Lee JH, Kim SJ, et al. Clinicopathologic characteristics and prognostic factors in 10783 patients with gastric cancer. Gastric Cancer. 1998; 1(2): 125-133, doi: 10.1007/s101200050006, indexed in Pubmed: 11957056.

33. Kim DH, Kim SuMi, Hyun JK, et al. Changes in postoperative recurrence and prognostic risk factors for patients with gastric cancer who underwent curative gastric resection during different time periods. Ann Surg Oncol. 2013; 20(7): 2317-2327, doi: 10.1245/s10434-012-2700-0, indexed in Pubmed: 23677605.

34. Marrelli D, Stefano ADe, Manzoni Gde, et al. Prediction of Recurrence After Radical Surgery for Gastric Can- cer. Ann Surg. 2005; 241(2): 247-255, doi: 10.1097/01. sla.0000152019.14741.97.

35. Otsuji E, Kuriu Y, Ichikawa D, et al. Time to death and pattern of death in recurrence following curative resection of gastric carcinoma: analysis based on depth of invasion. World J Surg. 2004; 28(9): 866-869, doi: 10.1007/s00268004-7359-7, indexed in Pubmed: 15593458.

36. Xue L, Chen XL, Lin PP, et al. Impact of capillary invasion on the prognosis of gastric adenocarcinoma patients: A retrospective cohort study. Oncotarget. 2016; 7(21): 31215-31225, doi: 10.18632/oncotarget.9101, indexed in Pubmed: 27145279.

37. Deng J, You Q, Gao Y, et al. Prognostic value of perineural invasion in gastric cancer: a systematic review and metaanalysis. PLoS One. 2014; 9(2): e88907, doi: 10.1371/journal.pone.0088907, indexed in Pubmed: 24586437.

38. Yu Jll, Lim DoH, Ahn YC, et al. Effects of adjuvant radiotherapy on completely resected gastric cancer: A radiation oncologist's view of the ARTIST randomized phase III trial. Radiother Oncol. 2015; 117(1): 171-177, doi: 10.1016/j. radonc.2015.08.009, indexed in Pubmed: 26299196.

39. Agolli L, Maurizi Enrici R, Osti MF. Adjuvant radiochemotherapy for gastric cancer: Should we use prognostic factors to select patients? World J Gastroenterol. 2016; 22(3): 1131-1138, doi: 10.3748/wjg.v22.i3.1131, indexed in Pubmed: 26811652.

40. Dikken JL, van Sandick JW, Swellengrebel HM, et al. Neo-adjuvant chemotherapy followed by surgery and chemotherapy or by surgery and chemoradiotherapy for patients with resectable gastric cancer (CRITICS). BMC Cancer. 2011; 11(6): 329-1013, doi: 10.1186/1471-240711-329, indexed in Pubmed: 21810227. 